\title{
Turbulent energy dissipation rates observed by Doppler MST Radar and by rocket-borne instruments during the MIDAS/MaCWAVE campaign 2002
}

\author{
N. Engler, R. Latteck, B. Strelnikov, W. Singer, and M. Rapp \\ Leibniz Institute of Atmospheric Physics, Kühlungsborn at University of Rostock e.V., Schlossstr. 6, 18225 Kühlungsborn, \\ Germany
}

Received: 22 December 2004 - Revised: 17 March 2005 - Accepted: 22 March 2005 - Published: 3 June 2005

\begin{abstract}
During the MIDAS/MaCWAVE campaign in summer 2002 we have observed turbulence using Doppler beam steering measurements obtained from the ALWIN VHF radar at Andøya/Northern Norway. This radar was operated in the Doppler beam steering mode for turbulence investigations during the campaign, as well as in spaced antenna mode, for continuously measuring the background wind field. The real-time data analysis of the Doppler radar backscattering provided the launch conditions for the sounding rockets. The spectral width data observed during the occurrence of PMSE were corrected for beam and shear broadening caused by the background wind field to obtain the turbulent part of the spectral width. The turbulent energy dissipation rates determined from the turbulent spectral width vary between 5 and $100 \mathrm{mWkg}^{-1}$ in the altitude range of $80-92 \mathrm{~km}$ and increase with altitude. These estimations agree well with the in-situ measurements using the CONE sensor which was launched on 3 sounding rockets during the campaign.
\end{abstract}

Keywords. Meteorology and atmospheric dynamics (Middle atmospheric dynamics; Turbulence; Instruments and techniques)

\section{Introduction}

The MIDAS/MaCWAVE campaign of ground-based and rocket-borne investigations of the upper mesosphere and lower thermosphere took place in June and July 2002 at the Andøya Rocket Range located near Andenes, Norway $\left(69^{\circ} \mathrm{N}, 16^{\circ} \mathrm{E}\right)$. During this collaborative campaign two special investigative topics were focused on. The MIDAS program concentrates on the small-scale dynamical and microphysical processes near the summer mesopause (Blix et al., 2003). The MaCWAVE program during summer 2002 carried out investigations of gravity wave influences on

Correspondence to: N. Engler

(engler@iap-kborn.de) dynamics of the summer mesopause structure and variability (Goldberg et al., 2004).

The ALWIN VHF radar was used to observe polar mesospheric summer echoes (PMSE) during summer 2002. It was running continuously throughout the whole summer period and with a special program during the campaign. The observation during the campaign provides a long-term data set covering Doppler spectral width for turbulence investigations and spaced antenna wind measurements. The analysis of the strong radar echoes (PMSE) can be used to estimate turbulence parameters in the upper mesosphere and lower thermosphere by estimating the turbulent part of the Doppler spectral width. During the special program the Doppler observation sequence was optimized to obtain Doppler echoes in a high temporal resolution for determinig suitable launch conditions and for turbulence investigations.

Mesospheric summer echoes (MSE) were reported for the first time by Czechowsky et al. (1979) for mid-latitudes in the Harz mountains $\left(52^{\circ} \mathrm{N}, 10^{\circ} \mathrm{E}\right)$ and by Ecklund and Balsley (1981) for polar latitudes at Poker Flat $\left(65^{\circ} \mathrm{N}, 145^{\circ} \mathrm{E}\right)$. From this time, lots of work has been done for a better understanding of these strong radar echoes; a recent review summarizes the most important results of these investigations (Rapp and Lübken, 2004).

Radio waves are backscattered by electron density irregularities with a vertical size of about half of the radar wavelength. In general, these irregularities are in the viscous subrange of turbulence and will be destroyed by molecular diffusion. The appearance of strong radar echoes in the upper mesosphere is connected to very low temperatures in the mesopause during the arctic summer (Lübken et al., 2002). It is assumed that the temperature in the PMSE layer is below $150 \mathrm{~K}$ and the saturation of water vapor with respect to ice is larger than unity (Körner and Sonnemann, 2001; Lübken et al., 2002), which means that the atmospheric condition is suitable for ice particles to grow. These ice particles can reduce the electron mobility and they are responsible for the existence of small-scale VHF radio wave scatterer (Cho and Röttger, 1997). 
Table 1. Experimental parameters of the ALWIN MST radar used during the MIDAS/MaCWAVE campaign.

\begin{tabular}{ll}
\hline Radar parameter & \\
\hline Frequency & $53.5 \mathrm{MHz}$ \\
Peak power & $36 \mathrm{~kW}$ \\
Beam width (FWHM) & $6^{\circ}$ \\
Duty cycle & $5 \%$ \\
Pulse repetition frequency & $1.45 \mathrm{kHz}$ \\
Puls length & $300 \mathrm{~m}$ \\
\hline Experiment parameter & \\
\hline height range & $72-98 \mathrm{~km}$ \\
height resolution & $300 \mathrm{~m}$ \\
tilt directions & vertical \\
& $\mathrm{NW}, \mathrm{SE}, \mathrm{NE}, \mathrm{SW}$ \\
tilt angle & $7^{\circ}, 14^{\circ}$ \\
Code & $16-\mathrm{bit} \mathrm{Complementary} \mathrm{Code}$ \\
Length of time series & 256 \\
coherent integration & 64 \\
Nyquist frequency $f_{N}$ & $11.30 \mathrm{~Hz}$ \\
Frequency resolution & $\Delta f=0.088 \mathrm{~Hz}$ \\
maximum radial velocity $v_{\text {rad }}$ & $31.70 \mathrm{~m} \mathrm{~s}-1$ \\
Velocity resolution & $\Delta v=0.25 \mathrm{~m} \mathrm{~s}-1$ \\
\hline
\end{tabular}

For the analysis of turbulence in the upper mesosphere between 70 and $92 \mathrm{~km}$ the Doppler radar echoes were recorded and the spectral parameters, such as echo power, Doppler shift, and spectral width, were estimated from the received time series. The variability of the random motion of scattering entities in the size of the Bragg scale of the radar results in a distribution of radial velocities. The Doppler spectral width parameter describes the fluctuations of the velocities of the scatterer in the observed volume which is determined by turbulence, horizontal background wind and atmospheric waves. The turbulent fraction of the observed spectral width can be achieved by correcting the influence of the background wind and wind shear (Hocking, 1983a; Nastrom, 1997; Nastrom and Eaton, 1997). Hence, the Doppler spectral width determined by radar observations can be used as an indicator of turbulence in the atmosphere, assuming that there is no other generating mechanism than active or fossil turbulence (Rapp and Lübken, 2004).

The estimation of turbulent parameters derived from radar backscattering has been discussed in detail previously in, for example, Hocking (1983a,b, 1985, 1999). The description of the determination of turbulence by radar investigations presumes that the observed volume is homogeneously filled with turbulent eddies. Furthermore, the turbulent part of the observed spectral width is directly related to the turbulent energy dissipation rate at the given altitude.

The CONE sensor was developed for combined measurements of density fluctuations of neutrals and electrons. A detailed description of the progress in the data analysis of neutral air density fluctuations is given by Strelnikov et al.
Table 2. Launch times of the sounding rockets during the MIDAS/MaCWAVE campaign in 2002. The apogee was reached $3 \mathrm{~min}$ after the launch of the rockets.

\begin{tabular}{lll}
\hline Rocket flight & Date & Time \\
\hline MM-MI-12 & 02-Jul-2002 & 01:44 UT \\
MM-MI-24 & 05-Jul-2002 & 01:10 UT \\
MM-MI-25 & 05-Jul-2002 & 01:42 UT \\
\hline
\end{tabular}

(2003). The authors were able to identify turbulent activities in an altitude range of 70-90 km from these in-situ measurements.

The turbulence parameters are discussed here in order to evaluate the turbulent energy dissipation rates derived from spectral width of the received radar echoes. Furthermore, we compare the estimated turbulent energy dissipation rates with the in-situ measurements of Rapp et al. (2004) during the MIDAS/MaCWAVE campaign, as well as with a climatological mean from several rocket launches by Lübken et al. (2002).

In Sect. 2 we discuss the setup of the radar experiment and in Sect. 3 the theoretical analysis is introduced for the estimation of turbulence parameters derived by radar observations. Section 4 provides the obtained results and shows the comparison of the radar data to rocket-borne results. The discussion is following in Sect. 5.

\section{Experimental Method}

The ALWIN MST radar operates at a frequency of $53.5 \mathrm{MHz}$ and can be configured in Doppler beam steering mode (DBS) or in spaced antenna mode (SA). The radar is designed for continuous operation, and during the campaign DBS and SA modes were set up in an alternate regime. In DBS mode the radar beam was pointing vertically and towards north-east, south-west, south-east, and north-west, with an off-zenith angle of $7^{\circ}$ and towards north-west with $14^{\circ}$. The full-width at half-maximum (FWHM) of the radar beam is determined to $6^{\circ}$ for the transmitting and the receiving beam in DBS mode.

The radar antenna consists of an array of 144 4-element Yagi antennas. The antennas are arranged in a $12 \times 12$ grid with subsystems consisting of 4 antennas. A detailed description of the radar is given by Latteck et al. (1999). For the DBS observations the whole antenna was used for transmission and receiving, whereas in the SA configuration the whole antenna was only used for transmission, and three subarrays of $6 \times 4$ antennas were used for receiving the radar signal. Table 1 gives a short overview of the parameters used in this campaign for the ALWIN MST radar.

In the present study, DBS measurements provide the observed spectral width, where during the countdown for the rocket launches the vertical beam was set up with a high temporal resolution. In this period, the radar beam was steered vertically, as well as $7^{\circ}$ off-zenith towards NW/SE and $14^{\circ}$ off-zenith towards $\mathrm{NW}$, into the direction of the 
rocket trajectory. Due to the lack of Doppler wind measurements the background wind field for the spectral broadening correction was generated from SA using the full-correlation analysis after Briggs (1984) in a suitable time resolution.

Table 2 gives an overview of the sounding rockets launched during the campaign.

A detailed description about the rocket launches during the MIDAS/MaCWAVE campaign is given in Rapp et al. (2004).

\section{Data analysis}

The returned DBS radar echoes were analyzed using the correlation method after Doviak and Zrnic (1993) to determine the spectral parameters. After this analysis a careful selection of the data was applied before further analysis. Only data values with a Signal-to-Noise ratio (SNR) larger than $0 \mathrm{~dB}$ were chosen as reliable estimates for further analysis, and the median profiles were prepared with at least three data points in each corresponding range gate during the averaging time period of $20 \mathrm{~min}$.

The variance of the radial velocity is described by the spectral width parameter of the radar echo and is determined by turbulent fluctuations and other mentioned contributions in the observed volume. The scatterers are randomly moving due to neutral air turbulence and atmospheric waves which increase the variance of the observed Doppler velocities. The observed spectral width in velocity units is given as

$\sigma_{o b s}=\frac{\lambda}{2} f_{(1 / 2) o b s}$,

where $f_{(1 / 2) o b s}$ is the half-power half-width of the Doppler spectra in the frequency domain and $\lambda$ the radar wavelength. If the beamwidth of the transmitting radar beam is very small, then only turbulent fluctuations in the atmosphere cause the spectral broadening and the contribution of the background wind can be neglected. The spectral width from a radar beam with a larger beamwidth, which holds for the radar with a half-power full-width of $6^{\circ}$ in $80 \mathrm{~km}$ altitude and a range resolution of $300 \mathrm{~m}$, is also influenced by broadening effects due to horizontal wind speed and wind shear. Equation (2) displays the contributing parts which determine the observed spectral width $\sigma_{o b s}^{2}$ :

$$
\begin{aligned}
\sigma_{\text {obs }}^{2} & =\sigma_{\text {beam }}^{2}+\sigma_{\text {shear }}^{2}+\sigma_{\text {wave }}^{2}+\sigma_{\text {turb }}^{2} \\
& =\sigma_{\text {corr }}^{2}+\sigma_{\text {turb }}^{2} .
\end{aligned}
$$

The observed spectral width of the returned radar signal is mainly influenced by the mean motion of the background wind through the illuminated volume of the radar beam and by turbulence. The correction of beam and shear broadening is combined in the term of $\sigma_{\text {corr }}$ and the expression is given in the following subsection. An expression for the spectral width correction due to gravity waves is given by Hocking (1988), Murphy et al. (1994), and Nastrom and Eaton (1997). However, the influence of gravity waves on the broadening of the spectra is not considered in the present study because its actual occurrence and behavior during the observation is unknown.

The determination of the turbulent part of the spectral width $\sigma_{t u r b}$ which is related to the root-mean-square velocity

$v_{r . m . s}^{2}=\frac{\sigma_{t u r b}^{2}}{(2 \ln 2)}$

is the base for the calculation of the energy dissipated in the atmosphere because of turbulence. Therefore, several different methods are established in the literature, for example, the so-called "exact" method by Hocking (1983a) which uses the polar diagram of the radar beam, the background wind, and the aspect sensitivity for determining the correction factor. Another method, the dual-beamwidth method which is independent of the mean background wind, was introduced by VanZandt et al. (2002) for a calculation of the turbulent part with a narrow and a wide beam pointing into the same direction. For the study presented here, we use an approximation based on the analytical expression to determine the correction of the beam and shear broadening from the background wind field.

\subsection{Beam and shear broadening}

The formula used in this study for the broadening correction is given by Nastrom and Eaton (1997),

$$
\begin{aligned}
\sigma_{\text {cor }}^{2} & =\frac{\left(\theta_{0}^{(1 w)}\right)^{2}}{3} V^{2} \cos ^{2} \alpha \\
& -\frac{2\left(\theta_{0}^{(1 w)}\right)^{2}}{3} \sin ^{2} \alpha\left(V \frac{\partial V}{\partial z} R \cos \alpha\right) \\
& +\frac{\left(\theta_{0}^{(1 w)}\right)^{2}}{24}(3+\cos 4 \alpha-4 \cos 2 \alpha)\left(\frac{\partial V}{\partial z}\right)^{2} R^{2} \\
+ & \left(\frac{\left(\theta_{0}^{(1 w)}\right)^{2}}{3} \cos 4 \alpha+\sin ^{2} \alpha \cos ^{2} \alpha\right)\left(\frac{\partial V}{\partial z}\right)^{2} \frac{\Delta R^{2}}{12} .
\end{aligned}
$$

In this formula, $\theta_{0}^{(1 w)}$ is the one-way half-power halfbeamwidth, $V$ the horizontal wind speed, $\partial V / \partial z$ the vertical wind shear, $\alpha$ the zenith angle of the radar beam, $R$ the range and $\Delta R$ the range resolution. For the off-zenith pointing beams all terms are used in the correction term and for the vertically pointing radar beam the second, third and parts of the fourth term in Eq. (4) are zero. Hence, the wind shear broadening correction, depending on the range and range resolution, is also included for the vertical beam. In the calculation of the correction for beam and shear broadening the horizontal wind speed was taken from SA measurements as a half-hourly mean.

\subsection{Turbulent energy dissipation rate $\epsilon$}

The calculation of the turbulent energy dissipation rate is based on the analysis proposed by Hocking (1996). After 
applying the correction for beam and shear broadening, the turbulent energy dissipation rate can be calculated,

$\epsilon=0.47\left(\frac{\sigma_{t u r b}}{\sqrt{2 \ln 2}}\right)^{2} N\left(\frac{1}{c_{f}}\right)^{2 / 3}$,

where $N$ is the Brunt-Väisälä frequency. The Brunt-Väisälä frequency was calculated using the climatological temperatures obtained from rocket measurements (Lübken, 1999). Using the mean temperatures of falling spheres (Müllemann et al., 2003) during the campaign, no important differences could be recognized. The correction term $c_{f}$ accounts for the fact that some of the turbulent fluctuations are caused by high frequency gravity waves (Hocking, 1996, 1999). The correction depends on the radar characteristics, and for the ALWIN MST radar and mesospheric altitudes the factor $c_{f}$ is approximately 1.8 (Hocking, 1996).

We also have to discuss some estimations for the detection limits of turbulence by radar measurements. Due to experimental conditions the turbulent energy dissipation rate is limited because of several factors. Table 1 shows the conditions used for this experiment. The pulse repetition frequency (PRF) and the number of coherent integrations result in a signal spectra with a Nyquist frequency of $f_{N y}=11.30 \mathrm{~Hz}$ and a resolution of $\Delta f=0.088 \mathrm{~Hz}$. The Nyquist frequency corresponds to a maximum radial velocity is $v_{r}^{\max }=31.7 \mathrm{~ms}^{-1}$ and the spectral resolution of the velocity of $\Delta v_{r}=0.25 \mathrm{~ms}^{-1}$. The estimated error of the radial velocity results in a variance of the turbulent energy dissipation rate of $\Delta \epsilon=0.3 \mathrm{~mW} \mathrm{~kg}^{-1}$. From the averaging procedure the calculated variance is on the order of $0.1-10 \mathrm{~mW} \mathrm{~kg}^{-1}$. In this case, we can determine turbulent energy dissipation rates with an accuracy of $\Delta \epsilon=0.3 \mathrm{~mW} \mathrm{~kg}^{-1}$ but a much larger statistical variance is estimated for the averaged height profiles.

\subsection{Aspect sensitivity}

In general, radar echoes from scatterers at mesosphere altitudes are different in strength depending on the zenith angle of the beam pointing direction. This difference can be estimated in the aspect sensitivity parameter which defines the degree of anisotropy of the radar return, as pointed out by Röttger et al. (1981), Hocking (1989), and Hocking and Hamza (1997). The aspect sensitivity $\theta_{S}$ is calculated as (Hocking, 1989; Hocking et al., 1990)

$$
\sin ^{2} \theta_{S}=\frac{\sin ^{2} \alpha}{\ln \left(\frac{P(0)}{P(\alpha)}\right)}-\sin ^{2}\left(\frac{\theta_{0}^{(2 w)}}{\sqrt{\ln 2}}\right)
$$

where $\alpha$ is the tilting angle of the off-zenith beam and $\theta_{0}^{(2 w)}$ the two-way half-power half-beamwidth. Dividing $\theta_{0}^{(2 w)}$ by $\sqrt{\ln 2}$ leads to the $1 / e$ beamwidth which is used by Hocking et al. (1990). The term $\ln (P(0) / P(\alpha))$ defines the received power from the zenith over the power received from the tilted beam. A large aspect sensitivity factor $\theta_{S}$ denotes small aspect sensitivity and the scatterers are more isotropic.
In contrast, small aspect angles characterize anisotropic scatterers or specular reflections (Röttger et al., 1981; Hocking and Hamza, 1997).

The aspect sensitivity can be related to an idealized picture of the scattering eddies described by a quasi-isotropic ellipsoid with horizontal and vertical axis $l_{x}$ and $l_{z}$. Using the calculated aspect sensitivity we can estimate the anisotropy ratio of the scattering eddies $l_{x} / l_{z}$ according to the expression (Lesicar and Hocking, 1992; Lesicar et al., 1994; Hocking and Hamza, 1997)

$$
\left(\frac{l_{x}}{l_{z}}\right)^{2}=\left(\frac{\lambda^{2} / h^{2}}{8 \pi^{2} \sin ^{2} \theta_{S}}+1\right),
$$

where $h$ is the $e^{-1}$ half-depth of the eddy. The value of $h \simeq 0.15-0.32 \lambda$ was determined for MF radar observations at $2 \mathrm{MHz}$ (Hocking, 1987).

\section{Results}

Figure 1 shows the height-time-intensity plots of the echo power received with the vertically pointing radar beam for a period of $10 \mathrm{~h}$ around the launch times of the sounding rockets. During both periods a PMSE layer was observed by the radar between 82 and $88 \mathrm{~km}$. Additionally, Fig. 1 displays the high variability of the observed echo power quite well. The launches of the MIDAS sounding rockets are indicated by the vertical lines inserted into the figures. The rockets were launched during the occurrence of an PMSE layer which allows this comparable study of turbulence in the middle atmosphere. Figure 2 presents the echoes received with the north-westward pointing radar beam at the same time. The echo strengths of the oblique beam pointing into the direction of the trajectories of the sounding rockets (Rapp et al., 2004) are much weaker than those of the vertical beam and indicate aspect sensitive scatterer.

From these data mean height profiles were extracted as an average of $20 \mathrm{~min}$, which means $10 \mathrm{~min}$ before and after the rockets have reached their apogees. Figure 3 represents these profiles for the three MIDAS rockets for the vertical beam as well as the tilted beams pointing towards north-west and south-east. It can be clearly seen that the signal on 2 July is about $10 \mathrm{~dB}$ weaker than on $5 \mathrm{July}$, where a power maximum of $60 \mathrm{~dB}$ at $85 \mathrm{~km}$ can be observed. On 2 July the power maximum is located at lower altitudes at about $84 \mathrm{~km}$ as on 5 July.

The received signals from the off-zenith beams pointing towards north-west and south-east, shown in Fig. 3 as blue and red dashed lines, are about 10 to $20 \mathrm{~dB}$ weaker than the echo received from the zenith at nearly all altitudes. In this case, we can argue that the scattering process is highly aspect sensitive. Figure 4 shows the calculated height profiles of the aspect sensitivity parameter using the median power received from the vertical pointing beam, together with the power of the NW tilted beam (blue dashed line) and the power of the SE pointing beam (red dashed line) of 

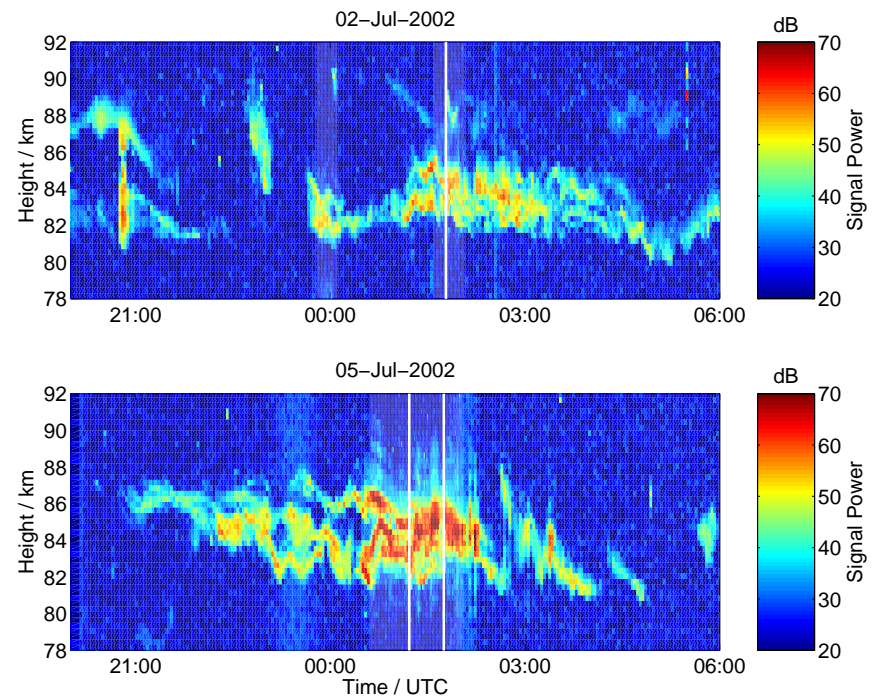

Fig. 1. Overview of the signal power received from the vertical beams on 2 July and 5 July 2002 as height-time-intensity plots. Shown are the periods of $10 \mathrm{~h}$ around the sounding rocket launches which are indicated by the vertical white lines.
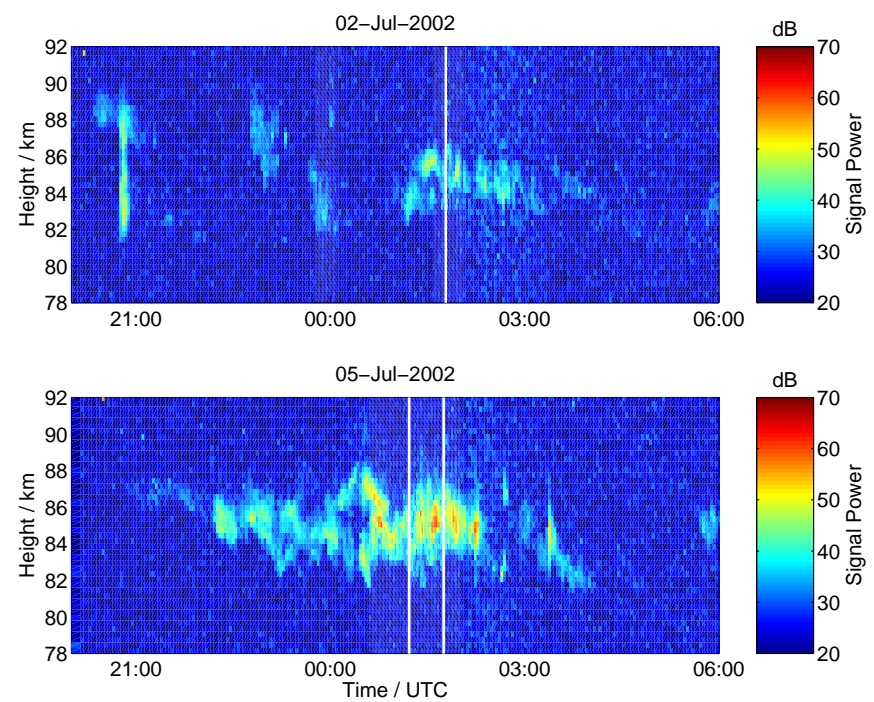

Fig. 2. Signal power for the same time interval as in Fig. 1 for the north-westward pointing beam. This is the direction of the trajectory of the sounding rockets during the MIDAS/MaCWAVE campaign.

Fig. 3. In Fig. 4 the white areas define the altitude ranges with an SNR larger than $0 \mathrm{~dB}$ of the vertical pointing radar beam. For the analysis of turbulence, only values with an SNR larger than $0 \mathrm{~dB}$ have been used in order to obtain reliable estimates. The aspect sensitivity parameter (Eq. 6) can be used as an indicator for the degree of anisotropy of the scattering eddies (Hocking, 1989; Hocking and Hamza, 1997). During the periods investigated here the aspect sensitivity parameter is on the order of $2-4^{\circ}$ in the lower
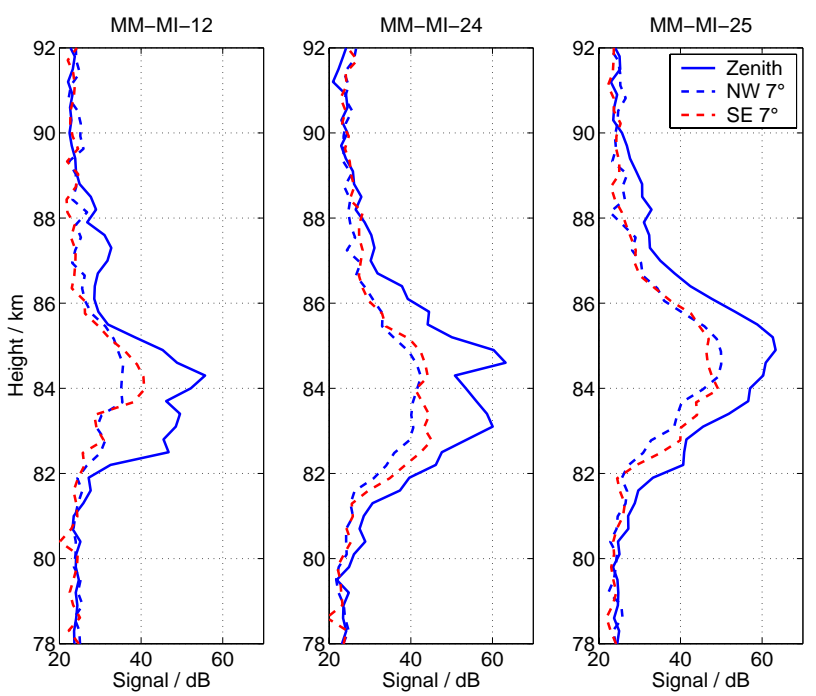

Fig. 3. Signal power profiles of the three rocket flights for the vertical and both off-zenith pointing beams as 20 min medians near the apogee time of the 3 sounding rockets launched during the MIDAS/MaCWAVE campaign. The solid lines show the signal received from the vertical beam and the dashed lines the signal from the $7^{\circ} \mathrm{NW}$ and SE beams.
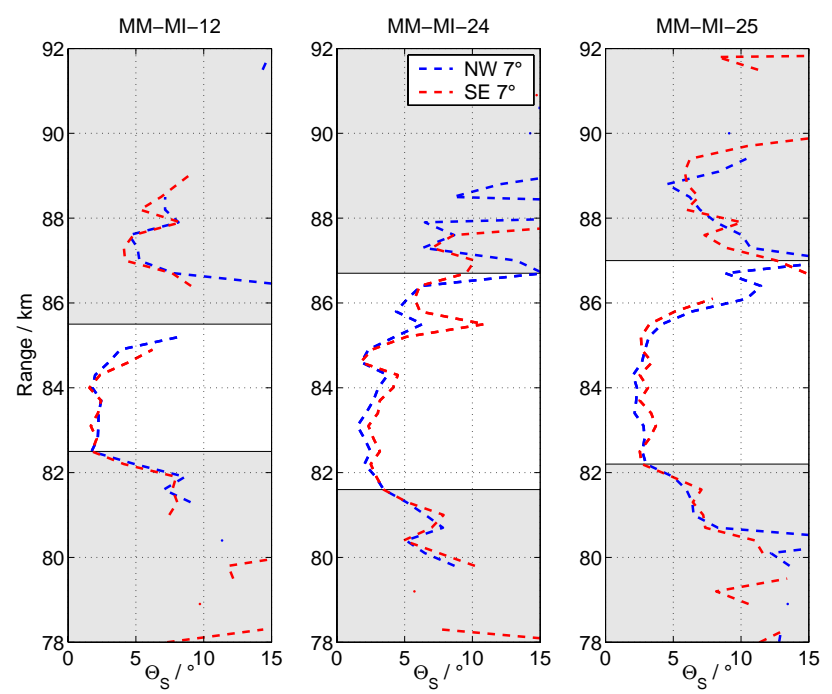

Fig. 4. Aspect sensitivity parameter calculated from the mean signal power for the three rocket flights. The white area defines the region where the SNR is larger than $0 \mathrm{~dB}$.

part of the observed range. At the upper part the aspect sensitivity parameter is increasing which indicates more isotropic turbulence in these heights. The aspect sensitivity values of the investigation shown here are also comparable to earlier observations (Czechowsky et al., 1988). In order to obtain a more detailed view on the anisotropy we have calculated the anisotropy ratio $l_{x} / l_{z}$ after Eq. (7) for the three periods of interest. The results are shown in Fig. 5. Here, we found an $l_{x} / l_{z}$ ratio larger than 5 in the altitudes of the maximum power. 

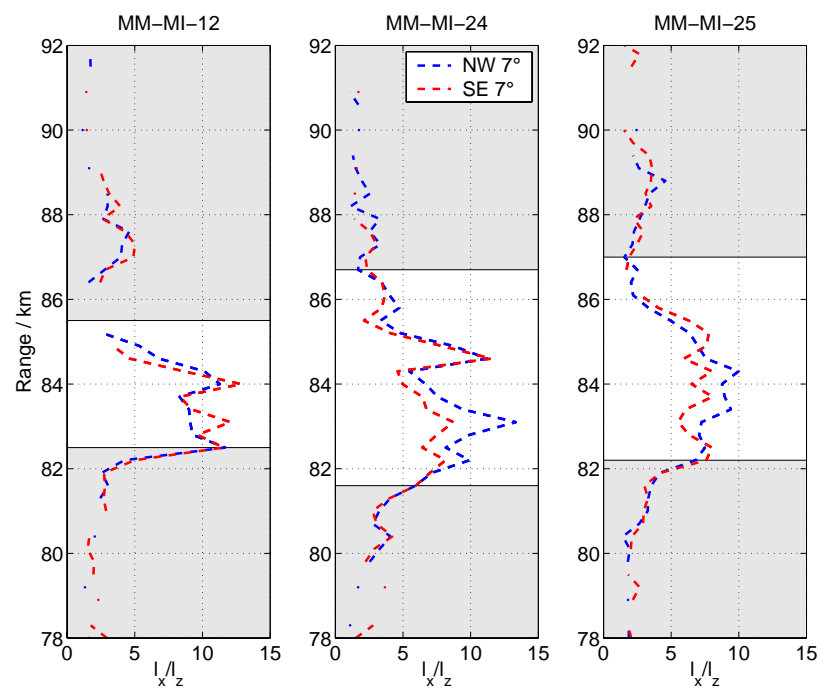

Fig. 5. Anisotropy ratio calculated from the mean aspect sensitivity shown in Fig. 4 for the three MIDAS rocket flights. The white area defines the values where the SNR is larger than $0 \mathrm{~dB}$. These parameters describe the degree of anisotropy of the scattering eddies.
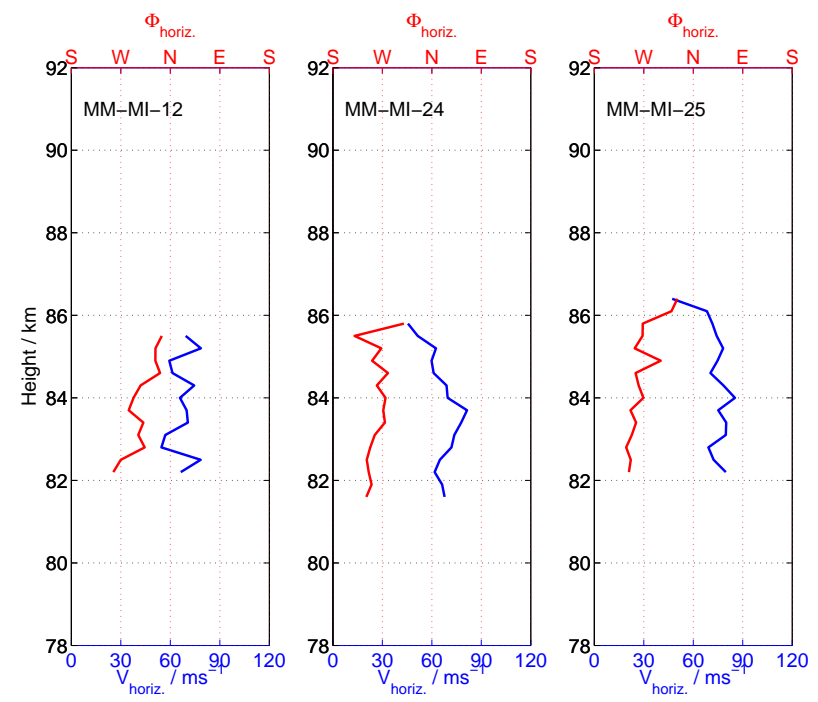

Fig. 6. Horizontal wind speed and direction as half-hourly mean measured by the Spaced-Antenna method.

The spectral broadening was determined according to Eq. (4) for all beam directions in the radar experiment. The mean background wind $V$ was derived from SA wind measurements as half-hourly means. The vertical gradient $(\partial V / \partial z)$ used in Eq. (4) was calculated from the horizontal wind speed $V$. Height profiles of the horizontal wind speeds and the wind directions for the periods of interest are shown in Fig. 6, where easterly (westward directed) winds with amplitudes of 70 to $80 \mathrm{~m} \mathrm{~s}^{-1}$ dominate. This is in agreement to former investigations at these altitudes during the polar summer (Czechowsky et al., 1988).
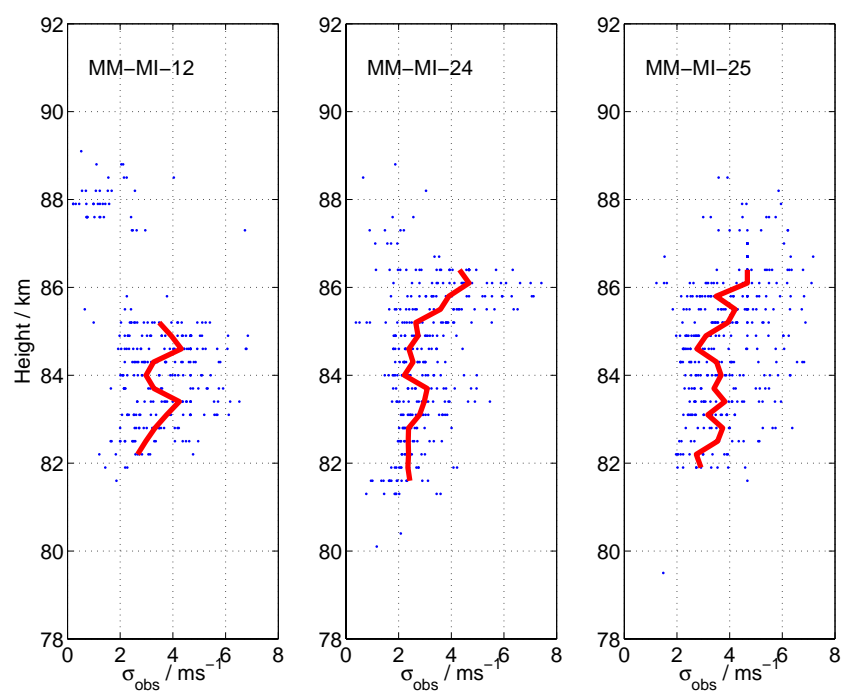

Fig. 7. Observed spectral width (individual values and median profiles) during the periods of the rocket flights. The dots represent the observed spectral width within the time window of $20 \mathrm{~min}$ and the median of the individual values used for the estimation of turbulent energy dissipation rates is shown as line. For further consideration only spectral width estimates are shown where the beam broadening correction could be applied and $\sigma_{\text {turb }}^{2} \geq 0 \mathrm{~m}^{2} \mathrm{~s}^{-2}$.

Figure 7 shows the individual spectral width values (blue dots) obtained in the 20-min period, together with the median value of the observed spectral width (solid line). As shown in this figure the variability is about $\pm 2 \mathrm{~m} \mathrm{~s}^{-1}$ in the observed 20-min periods. In Fig. 8 the median turbulent part of the spectral width is reduced by the correction term in the order of $1 \mathrm{~m} \mathrm{~s}^{-1}$. Looking at the individual values, the variation is still obvious and the correction term is in the order of $1-3 \mathrm{~m} \mathrm{~s}^{-1}$.

Although the beam-broadening correction is small, it has to be considered. The main contribution to the correction is given by the first term in Eq. (4) with the background wind speed. A significant influence on the spectral broadening can be introduced by the wind shear, while shear stress between layers in the atmosphere can lead to turbulence, as well. In the correction term the beam broadening resulting from the background wind and from the wind shear is also included for the vertical pointing beam, as shown in Eq. (4). The contribution of the wind shear broadening is on the order of $0.1-1 \%$ of the correction term for the vertical beam and $1-10 \%$ for the $7^{\circ}$-tilted beams.

According to Eq. (5) the turbulent energy dissipation rate can be estimated from the turbulent part of the spectral width obtained by radar observations. Figure 9 shows the $\epsilon$ values as 20-min medians around the apogee of the three rockets, where the blue solid line represents the energy dissipation calculated for the vertical pointing beam. Additionally, the in-situ results from the rocket estimations are shown as crosses for all three MIDAS sounding rockets. The results from these rocket flight data are discussed in more detail by 

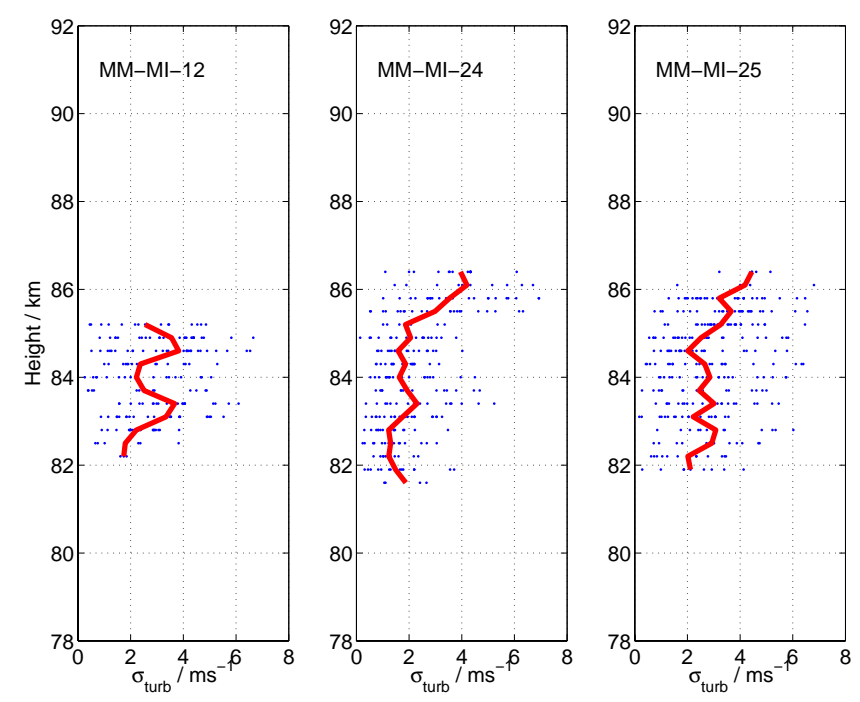

Fig. 8. Turbulent spectral width (individual values and median profiles) after applying the beam and shear broadening correction.
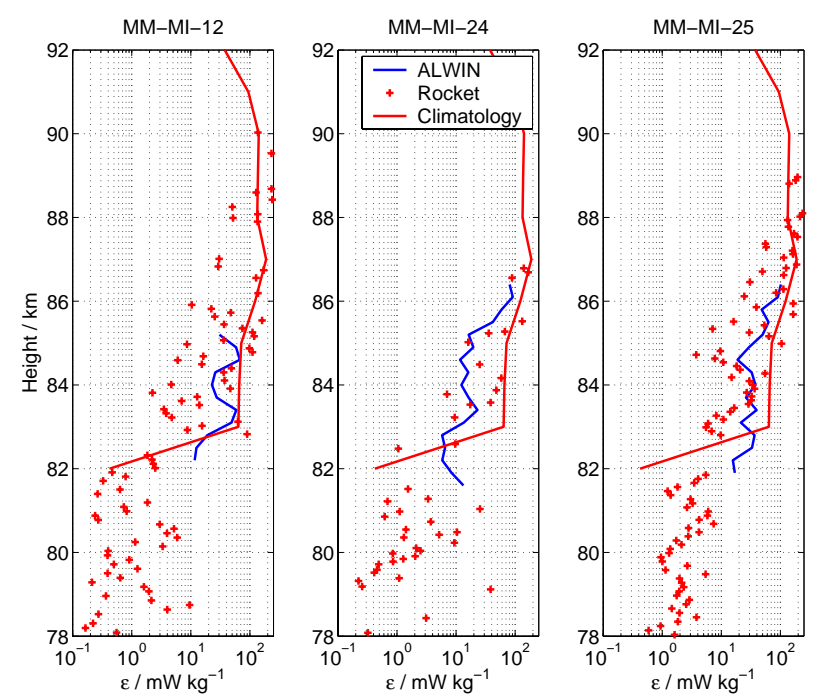

Fig. 9. Turbulent energy dissipation rates observed by different methods. The ALWIN VHF radar measurements are plotted together with the data obtained by the CONE sensor of the sounding rockets (Rapp et al., 2004) as well as the climatological mean of energy dissipation rates from rocket measurements (Lübken et al., 2002).

Rapp et al. (2004). Furthermore, we include mean energy dissipation rates derived from sounding rocket measurements within several years by Lübken et al. (2002). Figure 9 shows this detailed comparison of derived energy dissipation rates measured by radar and rockets for the first time.

For a better comparison the variance of the estimated values from radar observations is presented in Fig. 10. We have plotted the standard deviation $\sigma_{\epsilon}^{2}$ for the altitude range of the observed PMSE which is showing the variance around the time the rockets have reached their apogee. The variance is
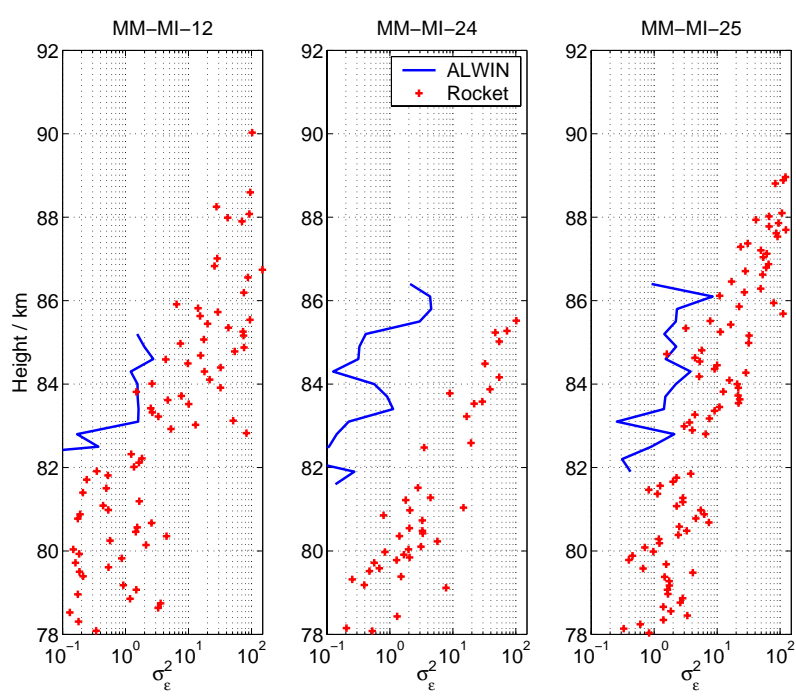

Fig. 10. Variance of turbulent energy dissipation rates for the average time period of $20 \mathrm{~min}$ around the rocket launches together with the estimated error of the rocket data analysis.

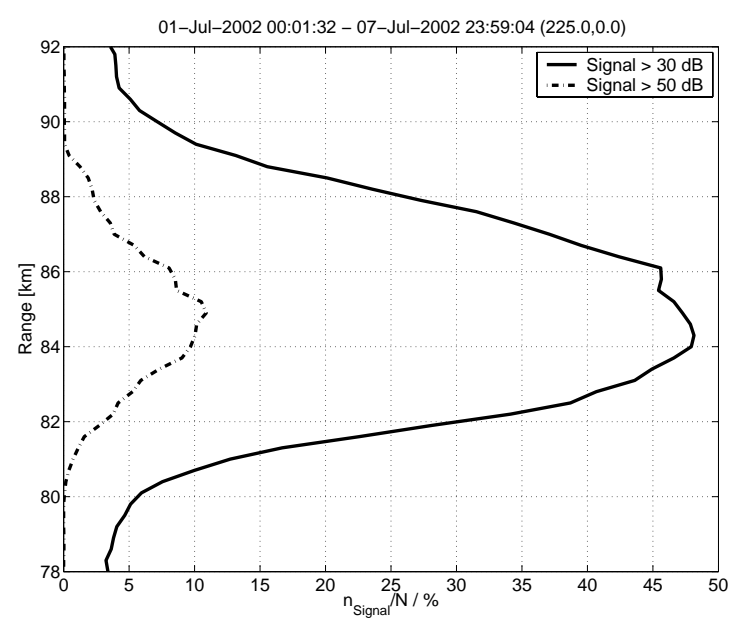

Fig. 11. Height distribution of signal power between 01/07/2002 and 07/07/2002 during the MIDAS/MaCWAVE campaign. The figure shows the number of received echo power of the vertical beam which are larger than 30 and $50 \mathrm{~dB}$. The occurrence rate $\left(n_{\text {Signal }}\right)$ is normalized to the total number of observations $(N)$.

small at lower altitudes and reaches up to $5 \mathrm{~m}^{2} \mathrm{~s}^{-2}$ at the upper boundary of the PMSE. Additionally, the errors of the insitu technique are also included in Fig. 10. For more details about this technique we refer to Lübken (1992) and Strelnikov et al. (2003).

For a statistical analysis during the period from 1 July until 7 July 2002, we have extracted the occurrence of PMSE and of energy dissipation. Figure 11 demonstrates the occurrence of PMSE plotted for two limits of signal strength. It shows the maximum occurrence of PMSE in an altitude between 83 and $86 \mathrm{~km}$ of more than $45 \%$ during this week with an echo power larger than $30 \mathrm{~dB}$. Figure 12 shows 


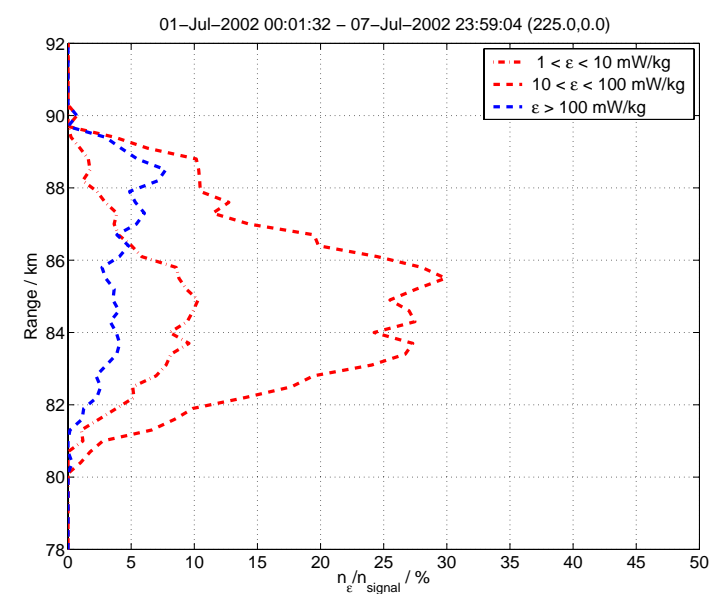

Fig. 12. Height distribution of turbulent energy dissipation rates for the same period shown in Fig. 11. The number of turbulent energy dissipation rates of three groups of dissipation strength $n_{\epsilon}$ are normalized by the PMSE occurrence larger than $30 \mathrm{~dB}$.

the occurrence of energy dissipation for the same period divided by the occurrence of PMSE with a signal power larger than $30 \mathrm{~dB}$. We have arranged the dissipation rates into three classes $\left(\epsilon<10 \mathrm{~mW} \mathrm{~kg}^{-1}, 10<\epsilon<100 \mathrm{~mW} \mathrm{~kg}^{-1}\right.$, and $\epsilon>100 \mathrm{~mW} \mathrm{~kg}^{-1}$ ), which might represent a reasonable classification. It is clearly seen that the middle class is in the same altitude range as the maximum of PMSE occurrence. Furthermore, we observe large energy dissipation mostly in the upper part of the PMSE while small dissipation is found in the lower part. The large energy dissipation due to turbulence in the upper part of the observed PMSE structure is evident with the in-situ rocket observations (Rapp et al., 2004).

The results from the analyzed week during the MIDAS/MaCWAVE campaign clearly show that energy dissipation due to turbulence is large at the upper edge of the PMSE. The number of observations in these altitude ranges are low for signals larger than $30 \mathrm{~dB}$ but it can be recognized that strong turbulence is located in the upper part of the observable echoes. In the whole altitude range of the PMSE medium turbulent energy dissipation is still the dominant fraction during the observed week.

\section{Discussion}

We have derived turbulent energy dissipation rates from Doppler spectral width measurements during the appearance of polar mesosphere summer echoes (PMSE) using VHF Doppler radar observations. The turbulent part of the spectral width is calculated and used for determining the turbulent energy dissipation rates. The energy dissipation was also measured by in-situ rocket experiments and we have compared these in-situ observations with continuous groundbased radar measurements.
We have concentrated our investigation on the turbulent part of the spectral width after eliminating the spectral broadening due to the background wind field. Figure 8 shows the turbulent parts as height profiles for the periods of the rocket flights. The influence of the background wind is on the order of $1-2 \mathrm{~m} \mathrm{~s}^{-1}$, which is clearly seen if comparing Fig. 8 to Fig. 7.

From the turbulent part of the spectral width we have calculated the turbulent energy dissipation rates shown in Fig. 9 for the three rocket launches of interest. We find energy dissipation rates which are in good agreement with the insitu rocket measurements (Rapp et al., 2004) which are also plotted in this figure. Additionally, we inserted the climatological means obtained by Lübken et al. (2002). For all launches the energy dissipation rates estimated by the VHF Doppler radar measurements fit well to the rocket data. During the first rocket flight at altitudes around $84 \mathrm{~km}$ no turbulence is observed by the rocket (Strelnikov et al., 2003) yet the radar detects a reduced value in the energy dissipation rate in the 20-min median. However, the radar observes velocity fluctuations in a volume defined by the beamwidth of the transmitted radar beam and the pulse length. In this case, the radar observations are averaged estimates in height and time while the rocket-borne instrument measures turbulence in a very small volume and for a short time scale during its flight. The turbulent energy dissipation rates obtained from both instruments are small at the bottom of the observed PMSE structure and increase with altitude (Fig. 9). The observation with an VHF radar is limited to the extension of the PMSE layer which is located in a 5-km altitude range (Fig. 3). However, the variability of the turbulent part of the spectral width is high, as shown in Fig. 8, for the 20-min period of interest. The 20-min median radar sounding profiles are in good agreement with the in-situ rocket observations.

Figure 10 shows the variability $\sigma_{\epsilon}^{2}$ in the period of $20 \mathrm{~min}$. The standard deviation for this period of averaging is small at lower altitudes while in higher altitudes the variation of the dissipation rates becomes larger. We would always expect a large variation of the turbulence parameters during the observation because of the high variability of the spectral width. Additionally, the errors from the rocket data analysis are inserted in Fig. 10. The curves are not directly comparable to the estimated variance of the radar observations but only comparable for the information used in the analyzing technique (Strelnikov et al., 2003). This figure shows that the variance of the energy dissipation and the error from the fit increase with altitude.

The results shown here demonstrate that VHF radar observations in the mesopause region are a suitable tool to estimate turbulence parameters continuously if a PMSE is present. The turbulent energy dissipation rates determined from the turbulent part of the spectral width are proven by in-situ rocket-borne observations and the results are in good agreement with the in-situ techniques.

The radar backscatter observed during all three rocket flights is highly aspect sensitive, as shown by the echo power observed with vertical and oblique radar beams (Fig. 3) and 
the $\theta_{S}$ values estimated from these data (Fig. 4). In general, the aspect sensitivity is decreasing (the aspect sensitivity factor $\theta_{S}$ is increasing) with altitude. In the following we discuss the relation between the observed aspect sensitivity and the possible backscatter processes.

The aspect sensitivity describes the anisotropy of the radar backscatter which can be originated from anisotropic turbulence or from specular reflection. Hocking and Hamza (1997) developed expressions which provide limits for the aspect ratio $l_{x} / l_{z}$ of an idealized scatterer to be originated from anisotropic turbulence. The aspect ratio (Eq. (12) in Hocking and Hamza, 1997) is a function of the radar wavelength (eddy scale), the vertical wind gradient, and the strength of turbulence. Using Eq. (7) (identical to Eq. (15) in Hocking and Hamza, 1997) the aspect ratio is converted to a lower limit of the aspect sensitivity factor $\theta_{S}$ which can be associated with anisotropic turbulence. Lower values would indicate that specular reflection is the dominant cause in radar backscatter.

A minimum energy dissipation rate of $\epsilon_{\min }=0.3 \mathrm{~mW} \mathrm{~kg}^{-1}$ was observed by the in-situ rocket measurements and we obtain a minimum aspect ratio of $l_{x} / l_{z}=1.7$, assuming a vertical wind gradient of $d V / d z=40 \mathrm{~m} \mathrm{~s}^{-1} \mathrm{~km}^{-1}$ for our VHF radar observations. Finally, the aspect ratio can be converted to a minimum aspect sensitivity factor of $\theta_{S} \simeq 15^{\circ}(h=0.32 \lambda$ assumed) which is considerably larger than the observed aspect sensitivity factor $\theta_{S}$ with values between $2^{\circ}$ and about $10^{\circ}$; $\theta_{S}$ values of about $15^{\circ}$ are reached only on the top of the PMSE layer. The aspect sensitivity factors obtained by VHF radar studies during the occurrence of PMSE are much lesser than the lower limit of the aspect sensitivity factor estimated from the aspect ratio using observed energy dissipation rates and wind shear. The aspect factor of 1.7 from the presented VHF studies is on the order of the values from MF studies which are around 1-4 (Hocking and Hamza, 1997). The difference between the aspect sensitivity factors could be related to different structures of the scatterer seen by VHF and MF radio wave scattering. The scatterer at MF frequencies around $2 \mathrm{MHz}$ are electron density disturbances generated by wind gradients and their scales are in the inertial subrange of turbulence. The VHF scatterers at $50 \mathrm{MHz}$ are electron density disturbances embedded in charged aerosol structures which reduce the electron mobility and sustain the refractive index disturbances at 3-m scales. The origin of VHF radar echoes might be different from that of MF radar echoes. Common volume and simultaneous observations by MF and VHF Doppler radars performed at Andenes in summer 2004 provide spectral width and aspect sensitivity data on both frequencies and will hopefully improve our understanding of these contradictory findings. This data analysis will be part of a separate paper.

The increase in the aspect sensitivity parameter in the upper part of the PMSE layer which conforms to lower aspect sensitivity seems to be a sign of enhanced turbulence in these altitudes. The high aspect sensitivity in the lower part of the PMSE could be due to horizontal layering of small-scale structures at lower altitudes, as suggested by Thrane et al.
(2004). The interpretation of the origin of the high aspect sensitivity within the PMSE still needs closer inspection in the future and further investigations will also take into account MF radar observations.

In the altitude range of PMSE occurrence we have observed turbulence with the radar and it is proved by rocket measurements. Therefore, we assume that the spectral broadening caused by turbulence is well estimated using the described analysis procedure.

\section{Conclusions}

The turbulent part of the observed Doppler spectral width of the VHF radar signal was used to estimate turbulent energy dissipation rates. The energy dissipation rates of the radar observations are limited in range to the extension of the PMSE layer. In the height between 83 and $86 \mathrm{~km}$ the estimates from radar investigations are in good agreement with the rocket data, as shown in the example presented here. We have observed turbulent energy dissipation rates inside the PMSE layer for the representative and comparable periods of the MIDAS rocket launches during the MIDAS/MaCWAVE campaign in 2002. We found dissipation rates at the lower edge of the observable echoes between $5-20 \mathrm{~mW} \mathrm{~kg}^{-1}$ and at the upper region of about $100 \mathrm{~mW} \mathrm{~kg}^{-1}$ which agree well with the in-situ measurements and the climatological mean.

In the discussion we also have pointed out that some of our observations still need further investigations, in particular, how we can improve the understanding of the aspect sensitivity of the scattering process at VHF frequencies and how we can exactly determine the quality of the energy dissipation rates obtained by radar observations. However, the data obtained by a VHF radar for short time periods of interest describe turbulence in the mesosphere well in comparison to single sounding rocket flights.

Ongoing radar observations will include turbulence investigations at different scales using, for instance, MF Doppler radar observations at $3 \mathrm{MHz}$. This radar allows a continuous investigation throughout the whole year since it does not depend on the occurrence of PMSE. Furthermore, the Bragg scale of this radar is within the inertial subrange of turbulence, where the first stages of turbulence could be studied.

Acknowledgements. The MIDAS project was supported by the DLR under the grant 50 OE 9802 and the Norwegian Research Council under grant 115980/431. The authors thank the staff of the Andøya Rocket Range for their support in the radar facilities and the rocket campaign and the members of the DLR Mobile Raketenbasis.

Topical Editor U.-P. Hoppe thanks a referee for his/her help in evaluating this paper.

\section{References}

Blix, T., Bekkeng, J., Latteck, R., Lübken, F.-J., Rapp, M., Schöch, A., Singer, W., Smiley, B., and Strelnikov, B.: Rocket probing of PMSE and NLC - results from the recent MIDAS/MaCWAVE campaign, Adv. Space Res., 31, 2061-2067, 2003. 
Briggs, B.: The analysis of spaced sensor records by correlation techniques, in: Middle Atmosphere Program: Handbook for MAP, edited by: Vincent, R., vol. 13, 166-186, 1984.

Cho, J. and Röttger, J.: An updated review of polar mesosphere summer echoes: Observation, theory, and their relationship to noctilucent clouds and subvisible aerosols, J. Geophys. Res., 102, 2001-2020, 1997.

Czechowsky, P., Rüster, R., and Schmidt, G.: Variations of mesosperic structures in different seasons, Geophys. Res. Lett., 6, 459-462, 1979.

Czechowsky, P., Reid, I., and Rüster, R.: VHF radar measurements of the aspect sensitivity of the summer polar mesosphere echoes over Andenes $\left(69^{\circ} \mathrm{N}, 16^{\circ} \mathrm{E}\right)$, Norway, Geophys. Res. Lett., 15, 1259-1262, 1988.

Doviak, R. and Zrnic, D.: Doppler Radar and Weather Observations, Academic Press, San Diego, CA, 2nd edn., 1993.

Ecklund, W. and Balsley, B.: Long-term observations of the arctic mesosphere with the MST radar at Poker Flat, Alaska, J. Geophys. Res., 86, 7775-7780, 1981.

Goldberg, R., Fritts, D., Wiliams, B., Lübken, F.-J., Rapp, M., Singer, W., Latteck, R., Hoffmann, P., Müllemann, A., Baumgarten, G., Schmidlin, F., She, C.-Y., and Krueger, D.: The MaCWAVE/MIDAS rocket and ground-based measurements of polar summer dynamics: Overview and mean state structure, Geophys. Res. Lett., 31, L24S02, doi:10.1029/2004GL019411, 2004.

Hocking, W.: On the extraction of atmospheric turbulence parameters from radar backscatter Doppler spectra - I. Theory, J. Atmos. Terr. Phys., 45, 89-102, 1983a.

Hocking, W.: Mesospheric turbulence intensities measured with HF radar at $35^{\circ} \mathrm{S}-$ II, J. Atmos. Terr. Phys., 45, 103-114, 1983 b.

Hocking, W.: Measurement of turbulent energy dissipation rates in the middle atmosphere by radar techniques: A review, Radio Sci., 20, 1403-1422, 1985.

Hocking, W.: Radar studies of small scale structure in the upper middle atmosphere and lower ionosphere, Adv. Space Res., 7, 10327-10338, 1987.

Hocking, W.: Two years of continuous measurements of turbulence parameters in the upper mesosphere and lower thermosphere made with a 2-MHz radar, J. Geophys. Res., 93, 24752491, 1988.

Hocking, W.: Middle atmosphere program, vol. 30, chap. Target parameter estimation, Handbook for MAP, 228-268, 1989.

Hocking, W.: An Assessment of the Capabilities and Limitations of Radars in Measurements of upper Atmosphere Turbulence, Adv. Space Res., 17, 1137-1147, 1996.

Hocking, W.: The dynamical parameters of turbulence theory as they apply to middle atmosphere studies, Earth Planets Space, 51, 525-541, 1999.

Hocking, W. and Hamza, A.: A quantitative measure of the degree of anisotropy of turbulence in terms of atmospheric parameters, with particular relevance to radar studies, J. Atmos. Solar-Terr. Phys., 59, 1011-1020, 1997.

Hocking, W., Fukao, S., Tsuda, T., Yamamoto, M., Sato, T., and Kato, S.: Aspect sensitivity of stratospheric VHF radio wave scatterers, particularly above $15-\mathrm{km}$ altitude, Radio Sci., 25, 613-627, 1990.

Körner, U. and Sonnemann, G.: Global three-dimensional modeling of the water vapor concentration of the mesosphere-mesopause region and implications with respect to the noctilucent cloud region, J. Geophys. Res., 106, 9639-9651, 2001.
Latteck, R., Singer, W., and Bardey, H.: The Alwin MST radar technical design and performances, in: Proc. 14th ESA Symp. on European Rocket and Ballon Programmes and related Research, edited by: Kaldeich-Schürmann, B., vol. ESA SP-437, 179-184, 1999.

Lesicar, D. and Hocking, W.: Studies of seasonal behaviour of the shape of mesosperic scatterers using a $1.98 \mathrm{MHz}$ radar, J. Atmos. Terr. Phys., 54, 295-309, 1992.

Lesicar, D., Hocking, W., and Vincent, R.: Comparative studies of scatterers observed by MF radars in the southern hemisphere mesosphere, J. Atmos. Terr. Phys., 56, 581-591, 1994.

Lübken, F.-J.: On the extraction of turbulent parameters from atmospheric density fluctuations, J. Geophys. Res., 97, 20385$20295,1992$.

Lübken, F.-J.: Thermal structure of the arctic summer mesosphere, J. Geophys. Res., 104, 9135-9149, 1999.

Lübken, F.-J., Rapp, M., and Hoffmann, P.: Neutral air turbulence and temperatures in the vicinity of polar mesosphere summer echoes, J. Geophys. Res., 107, D 15, 4273, doi:10.1029/2001JD000915, 2002.

Müllemann, A., Rapp, M., and Lübken, F.-J.: Morphology of turbulence in the polar summer mesopause region during the MIDAS/SOLSTICE campaign 2001, Adv. Space. Res., 31, 20692074, 2003.

Murphy, D., Hocking, W., and Fritts, D.: An assessment of the effect of gravity waves on the width of radar Doppler spectra, J. Atmos. Terr. Phys., 56, 17-29, 1994.

Nastrom, G.: Doppler radar spectral width broadening due to beamwidth and wind shear, Ann. Geophys., 15, 786-796, 1997, SRef-ID: 1432-0576/ag/1997-15-786.

Nastrom, G. and Eaton, F.: Turbulence eddy dissipation rates from radar observations at $5-20 \mathrm{~km}$ at White Sands Missile Range, New Mexico, J. Geophys. Res., 102, 19 495-19505, 1997.

Rapp, M. and Lübken, F.-J.: Polar mesosphere summer echoes (PMSE): Review of observations and current understanding, Atmos. Chem. Phys., 4, 2601-2633, 2004,

SRef-ID: 1680-7324/acp/2004-4-2601.

Rapp, M., Strelnikov, B., Müllemann, A., Lübken, F.-J., and Fritts, D.: Turbulence measurements and implications for gravity wave dissipation during the MaCWAVE/MIDAS rocket program, Geophys. Res. Lett., 31, L24S07, doi:10.1029/2004GL019325, 2004.

Röttger, J., Czechowsky, P., and Schmidt, G.: First low-power VHF radar observations of tropospheric, stratospheric, and mesospheric winds and turbulence at the Arecibo Observatory, J. Atmos. Terr. Phys., 43, 789-800, 1981.

Strelnikov, B., Rapp, M., and Lübken, F.-J.: A new technique for the analysis of neutral air density fluctuations measured in situ in the middle atmosphere, Geophys. Res. Lett., 30, L2052, doi:10.1029/2003GL018271, 2003.

Thrane, E. V., Blix, T. A., and Lie-Svendsen, Ø.: Can horizontal advection cause specular partial reflections of radio waves in the ionospheric D-region?, paper presented at the 35th COSPAR Scientific Assembly, Paris, France, 18-25 JULY, 2004.

VanZandt, T., Nastrom, G., Furumoto, J., Tsuda, T., and Clark, W.: A dual-beamwidth radar method for measuring atmospheric turbulent kinetic energy, Geophys. Res. Lett., 29, 1572, doi:10.1029/2001GL014283, 2002. 